\title{
Optimización de la Reacción en Cadena de la Polimerasa para la Detección del gen B1 de T. gondii
}

\author{
Polymerase Chain Reaction Optimization for Detection of gen B1 \\ Optimización de PCR para el gen B1 de T. gondii
}

Cortés Cortés Liliana Jazmín ${ }^{1}$, Hernández Castro Diana Carolina ${ }^{1}$, Mantilla Mónica², Medina María Isabel ${ }^{2}$, Duque Sofía ${ }^{1}$.

\section{Resumen}

Objetivo: Optimizar las condiciones de amplificación del gen B1 (35 copias en el genoma) para la detección de ADN de T.gondii en casos probables de toxoplasmosis cerebral. Materiales y métodos: Se realizó extracción de $\mathrm{ADN}$ a partir de exudado peritoneal de ratones inoculados con la cepa RH de T. gondii obteniendo $17 \mathrm{~mL}$ con una concentración inicial de $1 \times 10^{7}$ parásitos $/ \mathrm{mL}$. Se optimizaron las condiciones de PCR del gen B1. Resultados: Se obtuvo amplificación de un fragmento de $132 \mathrm{pb}$ a partir de ADN obtenido de diluciones seriadas desde $1 \times 10^{6}$ a $1 \times 10^{-1}$ parásitos por $\mathrm{mL}$, estableciéndose un límite de detección de 1 taquizoíto de T. gondii.

Palabras clave: toxoplasmosis, optimización, reacción en cadena de la polimerasa, gen B1, detección.

\section{Abstract}

Objective: This study aimed to optimize the conditions B1 gene amplification (35 copies in the genome) for the detection of. $T$ gondii DNA in probable cases of cerebral toxoplasmosis. Materials $y$ methods: DNA extraction was performed from the peritoneal exudate of mice inoculated with the RH strain of $T$. gondii obtaining an initial $17 \mathrm{~mL}$ to $1 \times 10^{7}$ parasites $/ \mathrm{mL}$. PCR conditions yielding B1 gene amplification of a fragment of $132 \mathrm{bp}$ DNA obtained from serial dilutions from $1 \times 10^{6}$ to $1 \times 10^{-1}$ parasites per $\mathrm{ml}$ were optimized, setting a limit of detection of $1 \mathrm{~T}$. gondii tachyzoite. Resulted: B1 gene amplification of a fragment of 132 bp DNA obtained from serial dilutions from $1 \times 10^{6}$ to $1 \times 10^{-1}$ parasites per $\mathrm{mL}$ were optimized, setting a limit of detection of 1 T. gondii tachyzoite.

Keywords: toxoplasmosis, optimization, chain reaction polymerase, B1 gene detection.

${ }^{1}$ Instituto Nacional de Salud. Dirección de Investigación en Salud Pública, Subdirección de

Investigación Científica y Tecnológica, Grupo de Parasitología.

2 Hospital Simón Bolívar E.S.E.

Correspondencia: jcortes@ins.gov.co. 


\section{Introducción}

La toxoplasmosis es una zoonosis mundial cuyos huéspedes definitivos son los felinos y como huéspedes intermediarios se encuentran el hombre y la mayoría de animales de sangre caliente (1). En el humano, la mayoría de las infecciones por T. gondii son subclínicas, sin embargo una infección severa puede ocurrir en los pacientes inmunocomprometidos dentro de los que se encuentran los pacientes con VIH/SIDA y con tumores malignos (2). En los pacientes con SIDA, a pesar de la terapia antirretroviral, la toxoplasmosis cerebral (TC) es la infección oportunista más frecuente (3).

La optimización de las condiciones de amplificación por PCR para el gen B1 de T. gondii, permitirá ser la base para realizar el diagnóstico molecular en pacientes con probable toxoplasmosis cerebral a través de la técnica de PCR en muestras biológicas de Liquido Cefalo Raquídeo (LCR) y sangre, ya que en Colombia, el diagnóstico de toxoplasmosis cerebral se realiza presuntivamente mediante hallazgos clínicos, radiológicos, serológicos y la respuesta a la terapia anti-Toxoplasma (4).

Es importante tener en cuenta que la mayoría de microorganismos que producen cuadros neurológicos en pacientes inmunosuprimidos (T. cruzi, Cryptococcus neoformans, Esptein-Barr entre otros) también causan sintomatología y se evidencian hallazgos radiológicos similares a los que se presentan en la TC, por lo que se resalta la importancia de realizar la PCR en LCR y sangre para hacer diagnóstico diferencial de TC y formular el tratamiento adecuado para el paciente (5).

\section{Materiales y métodos \\ Mantenimiento de la cepa RH de T. gondii en modelo animal}

Se realizó el mantenimiento de la cepa de referencia RH de T. gondii (ATCC 50174) a través de pases sucesivos en ratones de la cepa ICR-CD1, machos y hembras, de 18 a 20 días de edad, mediante la inoculación intraperitoneal con $0,3 \mathrm{~mL}$ de taquizoitos a una concentración de $1 \times 10^{6}$ parásitos $/ \mathrm{mL}$.

Se mantuvieron en el bioterio los animales inoculados, debidamente identificados, siguiendo las normas CICUAL (6). Se revisaron diariamente para detectar cambios en el comportamiento como letargia e inactividad y cambios físicos como irritación ocular, hepato o esplenomegalia, piloerección que evidenciaron la infección por T. gondii dándose así punto final al experimento y mediante eutanasia de los ratones en cámara de $\mathrm{CO}_{2}$ recolectar, del exudado de éstos, un mínimo $10^{6}$ taquizoítos del parásito/mL.

\section{Extracción de ADN parasitario}

Se realizó la extracción del ADN parasitario a partir del exudado peritoneal v/v con Clorhidrato de Guanidina, con una concentración de $1 \times 10^{6}$ parásitos/mL, con el kit PureLinkTM Genomic DNA Kits, siguiendo las instrucciones del fabricante así: Se resuspendieron $200 \mu \mathrm{l}$ de cada una de las muestras (cepa de referencia RH de T. gondii) en $200 \mu \mathrm{l}$ de Solución Salina estéril, se adicionaron $20 \mu \mathrm{l}$ de Proteinasa $\mathrm{K}$ a la muestra, no se adicionó RNAsa A a la muestra, porque puede producir inhibición, se mezcló suavemente con vórtex, se incubó por 2 minutos a temperatura ambiente, se adicionaron $200 \mu \mathrm{l}$ de PureLinkTM Genomic Lysis/Binding Buffer y se mezcló suavemente con vórtex. Se incubó a $55^{\circ} \mathrm{C}$ por 10 minutos para promover la digestión proteica. Se adicionaron $200 \mu \mathrm{l}$ de etanol (96-100\%) al lisado. Se mezcló suavemente con vórtex por 5 segundos.

Unión del $A D N$. Se tomó una columna PureLinkTM Spin Column del paquete. Se adicionó el lisado obtenido en el paso anterior. Se centrifugó la columna a $10.000 \mathrm{~g}$ por 3 minutos a temperatura ambiente. Se descartó el tubo colector y se transfirió la columna a un nuevo tubo colector.

Lavado de ADN. Se adicionaron $500 \mu \mathrm{l}$ de Buffer de Lavado 1 a la columna. Se centrifugó la columna 
a 10.000 g por 3 minutos a temperatura ambiente. Se descartó el tubo colector y se transfirió la columna a un nuevo tubo colector. Se adicionaron $500 \mu \mathrm{l}$ de Buffer de Lavado 2 a la columna. Se centrifugó la columna a máxima velocidad por 3 minutos a temperatura ambiente.

Elución del $A D N$. Se transfirió la columna a un tubo eppendorf estéril de $1,5 \mathrm{ml}$. Se adicionaron $100 \mu \mathrm{l}$ de buffer de elución del kit. Se incubó a temperatura ambiente por 2 minutos. Se centrifugó la columna a máxima velocidad por 3 minutos a temperatura ambiente. Se descartó la columna, el tubo colector es el que contiene el ADN. Se almacenó el $\mathrm{ADN}$ a $-40^{\circ} \mathrm{C}$.

Cuantificación de ADN. Se realizó la cuantificación del ADN obtenido mediante espectrofotómetro NanoDrop ${ }^{\text {тм }} 2000$ utilizando $2 \mu$ l de la muestra conservando la tensión superficial y la estática entre dos fibras ópticas sin la necesidad de utilizar diluciones.

\section{Optimización de la técnica de PCR.}

Se realizaron los análisis moleculares con el ADN del parásito, extraído a partir de exudado peritoneal de ratones inoculados cepa ICR-CD1.

Se utilizaron los oligonucleótidos reportados por Costa JM y Bretagne S (7) y tomando como base las condiciones de amplificación para el gen B1 informadas por Reischi y col. (8), se optimizaron las temperaturas óptimas de hibridación (Tms) de los oligonucleótidos, el tamaño del fragmento esperado, el tiempo de desnaturalización como el de extensión, el número de ciclos y el tiempo del ciclo de extensión final.

\section{Determinación de la sensibilidad de la técnica de PCR para la detección del gen B1 de T. gondii}

Se determinó la sensibilidad para la detección del gen $\mathrm{B} 1$ del parásito con diferentes concentraciones de ADN de la cepa RH de T. gondii. Para establecer la concentración de ADN obtenida se realizó la cuantificación por espectrofotometría con el NA-
NODROP 2000 y a partir de esta concentración se prepararon diluciones de $1 \times 10^{6}$ parásitos $/ \mathrm{mL}$, $1 \times 10^{5}$ parásitos $/ \mathrm{mL}, 1 \times 10^{4}$ parásitos $/ \mathrm{mL}, 1 \times 10^{3}$ parásitos $/ \mathrm{ml}, 1 \times 10^{2}$ parásitos $/ \mathrm{ml}, 1 \times 10^{1}$ parásitos/ $\mathrm{mL}, 1 \times 10^{0}$ parásitos $/ \mathrm{ml}, 1 \times 10^{-1}$ parásitos $/ \mathrm{mL}$; para determinar la mínima cantidad de ADN detectada por los oligonucleótidos del gen B1.

\section{Ensayos de exclusividad de la técnica de PCR} para la detección del gen B1 de T. gondii

Se determinó la especificidad de los oligonucleótidos mediante la amplificación de ADN de otros microorganismos como Plasmodium falciparum, Trypanosoma cruzi y Leishmania braziliensis.

\section{Resultados}

Luego de la extracción de ADN, se realizó la respectiva cuantificación obteniéndose una concentración promedio de ADN parasitaria de $28.5 \mathrm{ng} / \mathrm{mL}$. La mezcla de reacción para la amplificación del gen B1 fue optimizada así: GoTaq Hot Start Green Master Mix 1X, oligonucleótidos directo y reverso 4 pM y $5 \mu \mathrm{ADN}$ para un volumen final de 25 $\mu$ l. Las condiciones de amplificación optimizadas para el gen B1 se encuentran en la Tabla 1 .

Tabla 1. Condiciones de amplificación para el gen B1 de $T$. gondii

\section{CONDICIONES GEN B1}

Ciclos 50 ciclos

Acondicionamiento $95^{\circ} \mathrm{C} / 10$ minutos

Desnaturalización $95^{\circ} \mathrm{C} / 1$ minuto

Anillamiento $56^{\circ} \mathrm{C} / 1$ minuto

Extensión $72^{\circ} \mathrm{C} / 1$ minuto

Extensión final $72^{\circ} \mathrm{C} / 10$ minutos

La visualización del producto de amplificación, se realizó mediante una electroforesis en gel de agarosa (2\%), teńido con Gel Red.

En cuanto al límite de detección de PCR para detección de $T$. gondii la mínima concentración de ADN detectada por los oligonucleótidos del gen B1, corresponde a la dilución $10^{\circ}$, es decir a 1 taquizoíto de $T$. gondii. Figura 1. 
Figura 1. Límite de detección de PCR para detección de T. gondii y especificidad mediante amplificación de ADN obtenido de otros microorganismos como P. falciparum y T. cruzi.

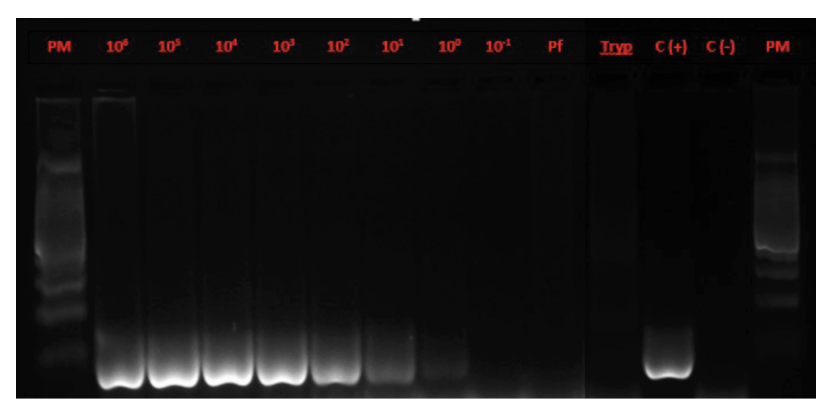

Mediante los ensayos de exclusividad de la técnica de PCR para la detección del gen B1 de T. gondii se determinó la especificidad de los oligonucleótidos mediante la amplificación de ADN obtenido de otros microorganismos como $P$. falciparum, $T$. cruzi y L. braziliensis. Al amplificar el ADN de estos organismos con los oligonucleótidos para el gen $\mathrm{B} 1$ bajo las mismas condiciones de amplificación no se observó ninguna reacción cruzada. Figuras 1 y 2.

Figura 2. Especificidad de PCR para detección de T. gondii mediante la amplificación de diferentes diluciones de ADN de $L$. braziliensis.

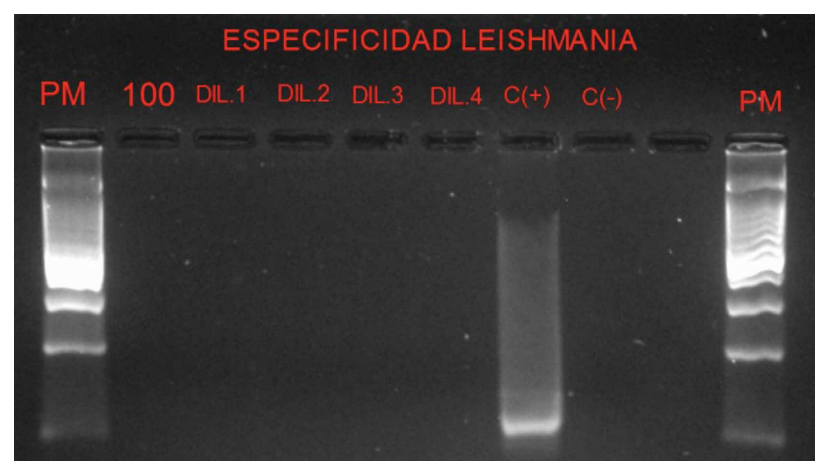

\section{Discusión}

La utilidad de los métodos biológicos moleculares ha sido investigada como herramienta complementaria del manejo clínico de afecciones como la toxoplasmosis cerebral. El uso de la técnica de PCR ha sido ampliamente recomendado para amplificar y posteriormente detectar el ADN de microorganismos en una variedad de líquidos y tejidos, particularmente aquellos que son difíciles para su detección directa por la complejidad de su aislamiento a partir de cultivos (9) o por el volumen reducido de la muestra, en cuyo caso ha demostrado ser muy útil (10).

La técnica de PCR para la detección del gen B1 de $T$. gondii, que se ha descrito puede ser utilizada para la confirmación diagnóstica de toxoplasmosis cerebral en muestras de sangre y LCR (11) la cual podría implementarse en los Laboratorios clínicos de Instituciones de Salud de tercer y cuarto nivel.

A través de este trabajo se optimizaron las condiciones de una técnica de PCR que permite la detección de $T$. gondii. Por medio de los ensayos de límite de detección se pudo establecer que esta técnica es capaz de detectar mínimo un taquizoíto presente en la muestra examinada y mediante los ensayos de exclusión se determinó que no se presentan reacciones cruzadas con otro patógenos (como Virus Epstein Barr, Virus JC, T. cruzi o Criptococcus neoformans entre otros) (12) que producen alteraciones cerebrales en pacientes inmunosuprimidos, mostrando que el gen B1 es altamente específico para T. gondii (13). 


\section{Referencias}

1. Priest J, Moss D, Arnold B, Hamlin K, Jones C, Lammie P. Seroepidemiology of Toxoplasma in a coastal region of Haiti: multiplex bead assay detection of immunoglobulin $\mathrm{G}$ antibodies that recognize the SAG2A antigen. Epidemiol Infect. 2015; 143(3): 618-30. doi: 10.1017/S0950268814001216.

2. Ahmadpour E, Daryani A, Sharif M, Sarvi S, Aarabi M, Mizani A, et. al. Toxoplasmosis in immunocompromised patients in Iran: a systematic review and meta-analysis.J Infect Dev Ctries. 2014; 15(12):1503-10. doi: 10.3855/jidc. 4796.

3. Meira C, Pereira-Chioccola V, Vidal J, de Mattos C, Motoie G, Costa-Silva TA, et. al. Cerebral and ocular toxoplasmosis related with IFN- $\gamma$, TNF- $\alpha$, and IL-10 levels. Front Microbiol. 2014; 5:492. doi: 10.3389/fmicb.2014.00492. eCollection 2014.

4. Tonini R, Vidal J, Vera L. Molecular diagnosis of cerebral toxoplasmosis: comparing markers that determine Toxoplasma gondii by PCR in peripheral blood from HIV-infected patients The Brazilian Journal of Infectious Diseases. 2010; 14(4): 346-50.

5. Anselmo L, Vilar F, Lima J, Yamamoto A, Bollela V, Takayanagui $\mathrm{O}$. Usefulness and limitations of polymerase chain reaction in the etiologic diagnosis of neurotoxoplasmosis in immunocompromised patients. J Neurol Sci. 2014; 346 (1-2):231-4. doi: $10.1016 /$ j.jns.2014.08.034.

6. Resolución 458 de 2011, Instituto Nacional de Salud.

7. Bretagne S, Costa JM, Vidaud M, Van Nhieu JT, Feith J. Detection of Toxoplasma gondii by Competitive DNA Amplification of Bronchoalveolar Lavage Samples. JID 1993;168 (6): 1585-88.
8. Reishi U, Bretagne S, Kruger D, Ernault P, Costa JM: Comparison of two targets for the diagnosis of Toxoplasmosis by real-time PCR using fluorescence resonance energy transfer hybridization probes. BMC Infect Dis. 2003; 3: 7 doi 10.1186/1471-2334-37.

9. Asgari Q, Keshavarz H, Shojaee S, Motazedian M, Mohebali M, Miri R, et al. In Vitro and In Vivo Potential of RH Strain of Toxoplasma gondii (Type I) in Tissue Cyst Forming. Iran J Parasitol. 2013; 8(3):367-75.

10. Taravati P, Lam D, Van Gelder R. Role of molecular diagnostics in ocular microbiology. Curr Ophthalmol Rep. 2013;1(4). doi: 10.1007/s40135-013-0025-1.

11. Bourdin C, Busse A, Kouamou E, Touafek F, Bodaghi B, Le Hoang P, Mazier, et al. PCR-based detection of Toxoplasma gondii DNA in blood and ocular samples for diagnosis of ocular toxoplasmosis. J Clin Microbiol. 2014; 52(11):3987-91. doi: 10.1128/JCM.01793-14.

12. Xiao J, Gao G, Li Y, Zhang W, Tian Y, et al. Spectrums of Opportunistic Infections and Malignancies in HIV-Infected Patients in Tertiary Care Hospital, China. PLoS ONE. 2013; 8(10): e75915. doi:10.1371/journal.pone.0075915.

13. Cortés LJ, Duque S, López MC, Moncada D, Molina D, Gómez-Marín JE, Gunturiz ML. Gene polymorphisms in the dihydrofolate reductase $(d h f r)$ and dihydropteroate synthase (dhps) genes and structural modelling of the dhps gene in Colombian isolates of Toxoplasma gondii. Biomedica. 2014; 34(4):556-66. doi: 10.1590/S0120-41572014000400008. 